\title{
A arbitragem como meio de solução de controvérsias no Comércio Internacional Brasileiro
}

\author{
Arbitration as a way to dispute in Brazilian International Trade
}

\author{
Danilo Vieira Vilela ${ }^{1}$ \\ Maísa Bonardi da Silveira ${ }^{2}$
}

\begin{abstract}
RESUMO
A arbitragem é um mecanismo extrajudicial de solução de conflitos, alternativo ao Poder Judiciário. Regulado, no Brasil, pela Lei 9.307, de 23 de setembro de 1996, este instituto possibilita um procedimento decisório eficaz aos litígios que envolvem direitos patrimoniais disponíveis, sendo utilizado de maneira vantajosa, dentre outras, nas demandas do comércio internacional. Nesse sentido, o presente artigo tem por objetivo analisar a evolução do instituto da arbitragem no ordenamento jurídico brasileiro, tendo-se como ponto de partida a ineficiência do sistema judiciário na solução de conflitos envolvendo contratos, cada vez mais complexos, no âmbito da globalização e da chamada "nova lex mercatoria". Pretende-se, dessa forma, compreender a importância do instituto da arbitragem para proporcionar ao comércio internacional brasileiro a segurança jurídica necessária ao seu fortalecimento, imprescindível para a retomada do desenvolvimento nacional. Parte-se de uma revisão bibliográfica com um enfoque descritivo de forma a se compreender o uso da arbitragem como a forma mais viável para a resolução das controvérsias do comércio internacional brasileiro. Para tanto utiliza-se de fontes doutrinárias, bem como dados estatísticos oriundos de entidades destinadas ao estudo da arbitragem no país, tendo-se como referencial teórico a obra de Antonio Carlos Rodrigues do Amaral, um dos pioneiros no estudo do Direito do Comércio Internacional no Brasil. Ao final conclui-se no sentido de que a opção pelo juízo arbitral é capaz de diminuir a sobrecarga do Judiciário e trazer benefícios econômicos aos litigantes e ao próprio Estado brasileiro.
\end{abstract}

\section{PALAVRAS-CHAVE:}

Meios adequados de solução de litígios, Arbitragem, Comércio Internacional, Brasil.

\begin{abstract}
Arbitration is an extrajudicial conflict resolution mechanism, alternative to the Judiciary. Regulated, in Brazil, by Law 9,307, of September 23, 1996, this institute enables an effective decision-making procedure to litigations involving available patrimonial rights, being used advantageously, among others, in the demands of international trade. In this sense, the present paper aims to analyze the evolution of the arbitration institute in the Brazilian legal system, taking as a starting point the inefficiency of the judicial system in the solution of conflicts involving increasingly complex contracts, in the scope of globalization and the so-called "new

\footnotetext{
1 Doutor em Direito Político e Econômico na Universidade Presbiteriana Mackenzie. Mestre em Direito Obrigacional Público e Privado pela Universidade Estadual Paulista (UNESP). Professor na Universidade do Estado de Minas Gerais (UEMG), unidade de Frutal, vinculado ao departamento de Ciências Sociais Aplicadas. Árbitro no Centro Brasileiro de Litígios Econômicos (CBLE). Advogado.

${ }^{2}$ Advogada. Bacharela em Direito pela Universidade do Estado de Minas Gerais (UEMG).
} 
lex mercatoria". In this way, we intend to understand the importance of the arbitration institute to provide Brazilian international trade with the legal security necessary for its strengthening, which is essential for the resumption of national development. It starts with a literature review with a descriptive focus in order to understand the use of arbitration as the most viable way to resolve the controversies of Brazilian international trade. For that, it uses doctrinal sources, as well as statistical data from entities destined to the study of arbitration in the country, having as a theoretical reference the studies of Antonio Carlos Rodrigues do Amaral, one of the pioneers in the study of International Trade Law in the Brazil. In the end, it is concluded that the option for arbitration is capable of reducing the burden of the Judiciary and bringing economic benefits to litigants and to the Brazilian State itself.

\section{KEYWORDS:}

Adequate means of dispute resolution, Arbitration, International Trade, Brazil.

\section{INTRODUÇÃO}

No final do século XX foi acentuado, no Brasil, o fenômeno da judicialização, responsável por concentrar a solução de diversos problemas sociais no Poder Judiciário, o que, apesar de ter assegurado o exercício da cidadania, provocou o aumento exacerbado das demandas a serem resolvidas judicialmente, causando, consequentemente um agravamento na morosidade e ineficiência do sistema.

Com isso, ganhou força a busca de caminhos diferentes para a efetivação da justiça, em harmonia com as novas modalidades de solução não jurisdicionais de conflitos, dentre os quais destaca-se a arbitragem, em relação a direitos patrimoniais disponíveis, o que revela ser assunto de amplo interesse social, empresarial e econômico.

A lei n ${ }^{\circ}$ 9.307, de 23 de setembro de 1996, foi responsável pela adequação do instituto às principais normas internacionais, consolidando a arbitragem como uma das mais importantes medidas legais, no campo dos métodos alternativos ao Poder Judiciário para solução de controvérsias, adotadas no Brasil. Neste instituto, as partes, por autonomia da vontade, investem poderes para que um ou mais particulares solucionem controvérsias que abordem direitos patrimoniais disponíveis, de modo que sua decisão se equipara à judicial e se reveste da garantia constitucional da coisa julgada material. 
O referido mecanismo extrajudicial abriga inúmeras vantagens para o cenário atual, pois além de oferecer decisões qualificadas, técnicas, normalmente sigilosas, específicas para cada caso, e formuladas por árbitros experientes na área de conflito, demandam muito menos tempo para serem concluídas.

Esses benefícios proporcionados pelo juízo arbitral podem ser aproveitados em vários litígios do cenário brasileiro, os quais, muitas vezes, demandam o sigilo, a celeridade e a especialidade que o Poder Judiciário não é capaz de oferecer.

Neste ponto, é possível evidenciar a importância da aplicação da arbitragem nos litígios que envolvem o comércio internacional, como meio de garantir maior segurança jurídica ao setor, imprescindível para a retomada do crescimento nacional.

Assim, o presente trabalho, desenvolvido por meio de pesquisa bibliográfica, realizada sob o método descritivo, por meio da análise e do registro das características do uso da arbitragem como forma de resolução dos conflitos do comércio internacional brasileiro, bem como sua relação com o cenário comercial nacional, busca apresentar o regime jurídico e as vantagens da adoção da arbitragem no país.

Parte-se, dessa forma, da identificação da arbitragem como meio adequado à solução de controvérsias no direito brasileiro (Resolução CNJ 125/2010), apresentando-se os avanços decorrentes da promulgação da lei 9.307, de 1996 para, a seguir, analisar de que forma, os novos contornos do comércio internacional pós-globalização fazem da arbitragem um meio eficiente à solução dos litígios no Brasil.

\section{A CRISE DO PODER JUDICIÁRIO E A ARBITRAGEM COMO MEIO ALTERNATIVO À SOLUÇÃO DE CONTROVÉRSIAS NO BRASIL}

Consoante dados do Conselho Nacional de Justiça $(\mathrm{CNJ})$, órgão responsável por supervisionar e controlar o Poder Judiciário no Brasil, o ano de 2017 foi concluído com 80,1 milhões de processos em tramitação, aguardando uma solução definitiva. Ademais, após 
análise, o referido órgão constatou que ainda que o Poder Judiciário fosse paralisado sem a entrada de novas demandas e mantida a produtividade dos magistrados e dos servidores, seriam necessários aproximadamente 2 anos e 7 meses de trabalho para zerar o acúmulo de processos (BRASIL, 2018, s.p).

Helena Delgado Ramos Fialho Moreira pontua:

De há muito já se ouve falar na necessidade de processarem-se urgentes e profundas mudanças no aparelhamento do Estado, visando uma atuação mais ágil e eficiente da Administração Pública nas áreas que lhe são mais afetas por natureza e, dentro delas, principalmente, naquela que tem ocupado crescente lugar de destaque nos questionamentos sociais: o da prestação de justiça - aqui traduzida pragmaticamente pelo dever estatal de apaziguar juridicamente os conflitos que surgem, tanto entre os cidadãos, como entre estes e o próprio Estado. (MOREIRA, 2009, p. 21).

No mesmo sentido, Juarez Freitas e Marco Félix Jobim apontam a fadiga enfrentada pelo modo jurisdicional de solução de litígios, alertando para o fato de que, sobretudo nos grandes negócios, não há tempo a esperar, de forma que todas as partes em conflito perdem com a demora (2015, p. 101).

Dessa forma, torna-se imprescindível que a solução dos litígios seja buscada não apenas nos meios judiciais, mas também nos extrajudiciais, havendo, portanto, a necessidade de coexistirem diferentes meios capazes de pacificar controvérsias. Assim:

Não basta para o jurisdicionado envolvido numa lide judicial que o Estado diga o
direito; torna-se imprescindível que esse direito seja conferido materialmente a quem
tem razão, isto é, que a pretensão se efetive através do instrumento colocado à
disposição do vencedor e que esteja em sintonia com os princípios constitucionais
processuais. Para tanto, faz-se mister que o acesso à justiça (entenda-se aqui a
expressão como meios diversos de pacificação de conflitos) seja amplo e irrestrito,
assim como a ordem jurídica oferecida deve necessariamente ser justa (capaz de
oferecer mecanismos hábeis à consecução rápida, segura e justa de uma pretensão
resistida ou insatisfeita. (FIGUEIRA JÚNIOR, 1999, p. 134).

Logo, a aplicação de métodos alternativos $^{3}$ para resolução de litígios, capazes de propiciar a pacificação social, representa uma temática de grande relevância prática, sendo também uma tendência global, já que é legítima, democrática, e capaz de ampliar e dar maior

\footnotetext{
${ }^{3}$ A Resolução no 125/2010, do Conselho Nacional de Justiça, ao incentivar e promover a ideia de "justiça multiportas", utilizou-se da expressão "métodos adequados” de solução de controvérsias. Assim, a partir de então, a arbitragem deve ser compreendida não como uma opção subsidiária ou alternativa à justiça estatal, mas como uma possibilidade realmente adequada, apta a oferecer uma solução tão ou mais eficiente que a atuação do Poder Judiciário.
} 
efetividade ao acesso à Justiça, na sua concepção de acesso à ordem jurídica justa e democrática. (TRISTÃO; FACHIN, 2009, p. 56).

Em verdade, a adoção de métodos alternativos de litígios apresenta uma série de vantagens, tais como: “confidencialidade, flexibilidade, experiência dos árbitros e mediadores, redução dos custos, preservação das relações comerciais, utilização de um único foro para a solução das disputas e a possibilidade de soluções colaborativas e criativas" (VILELA, 2018, p. 276).

Dentre os mecanismos resolutivos, destaca-se a heterocomposição, técnica que conta com a presença de terceiro imparcial, alheio ao interesse das partes, para solucionar a lide, cujas quatro modalidades são a mediação, a conciliação, a arbitragem e a jurisdição, sendo as três primeiras espécies de “Alternative Dispute Resolution” (FREITAS; JOBIM, 2015, p. 104).

$\mathrm{Na}$ arbitragem, objeto principal desse trabalho, a questão litigiosa será resolvida por terceiro ou terceiros, sempre em número ímpar, escolhido(s) privativamente pelas partes, os quais são denominados árbitros. Estes árbitros são qualificados para proferir tal decisão, mas não precisam ser advogados ou possuir conhecimentos jurídicos específicos (AMARAL, 2004, p. 340), além disso, "a atividade desenvolvida pelo árbitro é, em sua substância, idêntica à do juiz estatal, não havendo qualquer relação de hierarquia ou de subordinação entre eles" (WLADECK; AMARAL, 2011, p. 5).

A decisão pronunciada pelo juízo arbitral, a sentença arbitral, terá os mesmos efeitos dos julgados realizados pelo Poder Judiciário e não necessitará de homologação judicial, valendo, inclusive, como título executivo, se for condenatória (TRISTÃO; FACHIN, 2009, p. 57). Além disso, será proferida em prazo estipulado pelas partes ou, quando não convencionado, em seis meses, o que comprova a celeridade deste procedimento (art. 23 da lei $\mathrm{n}^{\circ}$ 9.307/96).

Nesse sentido, a arbitragem, revela-se como uma eficaz alternativa de evitar a movimentação da máquina do Judiciário, muito utilizada na seara internacional ao longo dos séculos, caracterizada por José Francisco Rezek como nada mais que "um mecanismo jurisdicional não judiciário" (REZEK, 2008, p. 349).

Por sua vez, Lafayette Rodrigues Pereira entende que: 
A arbitragem ou arbitramento (arbitrium) é o juízo (judicium) constituído por uma ou mais pessoas - indivíduos ou governos - escolhidos livremente pelas Partes contendoras, para decidirem o litígio ou controvérsias entre ellas [sic] existentes. (PEREIRA, 2017, p. 135).

Assim, o procedimento arbitral é alternativo e facultativo, utilizado para solucionar conflitos que abordam direitos patrimoniais disponíveis. Nele, as partes, por autonomia da vontade, investem poderes para que um ou mais particulares solucionem tais controvérsias, de modo que sua decisão se equipara à judicial e se reveste da garantia constitucional da coisa julgada material.

Este procedimento, como um meio alternativo de solução de litígios, permite que as partes escolham os julgadores e tenham um maior controle do caso. Tem como atributos a informalidade, o sigilo, a celeridade, a possibilidade de julgamento por equidade e a especialização dos árbitros, possuindo, assim, grande aceitação e tradição nas causas de grande complexidade (MARCO, 2005, p. 15). Nádia de Araújo, ao analisar os contratos internacionais, afirma que:

\begin{abstract}
A arbitragem é um meio jurídico de solução de controvérsias presentes ou futuras, baseado na vontade das partes envolvidas, as quais elegem por si mesmas e diretamente, ou através de mecanismos por elas determinados, árbitros para serem os juízes da controvérsia, confiando-lhes a missão de decidir de forma obrigatória o litígio através da prolação de um laudo arbitral. Ao final da arbitragem, idealmente, espera-se que o laudo seja cumprido espontaneamente. Sua natureza em nada se modifica em virtude de ser a arbitragem interna ou internacional. (ARAÚJO, 1997, p.90).
\end{abstract}

Assim, resta claro que no instituto jurídico da arbitragem, a solução do litígio é determinada pela intervenção de um terceiro, ou terceiros, por meio da solicitação dos litigantes, os quais pactuam, e estabelecem os limites, os procedimentos, prazos, e, inclusive, a lei a ser utilizada, para que, ao final, seja elaborada uma sentença arbitral que coloca um fim ao litígio, cumprindo, portanto, relevante papel na manutenção do equilíbrio social.

\title{
2.1. Natureza Jurídica da arbitragem
}

A natureza jurídica da arbitragem é um tema que gera divergências entre os doutrinadores brasileiros, que dividem seus posicionamentos entre natureza jurisdicional, contratual ou mista. 
Os autores que compreendem o instituto como de natureza jurisdicional, o definem como uma solução alternativa de conflitos, ou mesmo substitutiva ao poder estatal. Assim, Nelson Nery Junior explica que o árbitro exerce jurisdição pelo fato de aplicar o direito ao caso concreto e findar o conflito entre as partes (NERYJUNIOR, 2008, p.455).

Por outro lado, aqueles que entendem que a arbitragem possui natureza contratual, utilizam como base a autonomia da vontade, que resultaria em um acordo entre as partes, o qual refletiria uma obrigação de natureza eminentemente privada (MARCO, 2005, p. 18).

Por fim, aqueles que defendem a corrente mista expõem que a arbitragem teria, concomitantemente, natureza contratual e jurisdicional, e, nesse sentido, o acordo entre as partes determinaria a existência da jurisdição da arbitragem ${ }^{4}$.

Sobre a corrente mista, Schmittoff explica que:

There can never be Arbitration without an agreement of the parties to submit to this method of dispute settlement. This is a very fundamental proposition. [...] The arbitrator, as a private judge chosen by the parties or appointed in accordance with the Arbitration agreement, must approach the issues before him in the same spirit as a judge appointed by de State. He must be absolutely impartial (SCHMITTHOFF, 1990, p. 650).

Fica evidente, portanto, que a questão da natureza jurídica da arbitragem não foi pacificada, embora a grande maioria da doutrina brasileira tenha aderido ao entendimento da sua natureza jurisdicional.

\section{A ARBITRAGEM NO DIREITO BRASILEIRO}

A prática da arbitragem no Brasil é reconhecida pela doutrina desde o período da colonização portuguesa, momento em que se utilizava o conjunto legal denominado “Ordenações Filipinas", sistema que se manteve em vigor mesmo após a independência, em

\footnotetext{
${ }^{4}$ Há ainda quem defenda a existência de uma quarta teoria: a teoria autônoma, segundo a qual a arbitragem internacional possuiria natureza autônoma, "sendo completamente desvinculada de qualquer ordenamento estatal, possuindo, entretanto, o reconhecimento da comunidade internacional, no que se refere a conflitos transnacionais" (FERREIRA; ROCHA; FERREIRA, 2019, p. 43).
} 
1822. Regulamentava a recorribilidade da sentença arbitral, bem como a necessidade de homologação de decisão arbitral pelo Judiciário (RIBEIRO, 2006, p. 25).

Ainda no período Imperial, a Constituição de 1824, em seu artigo 160 estabelecia que nas causas "cíveis e penais civilmente intentadas, poderão as partes nomear Juízes Árbitros. Suas sentenças serão executadas sem recurso, se assim convencionassem as mesmas Partes" (FIGUEIRA JUNIOR, 1997, p.24).

Nos primeiros tempos de sua independência política, era obrigatório o procedimento arbitral em questões que tratavam sobre seguro e locações de serviços.

Sobre o assunto, Humberto Theodoro Junior ensina que em 1850, com a edição do Código Comercial, ficou consolidado que o juízo arbitral era obrigatório para a solução de conflitos que envolvessem a locação mercantil, de relações entre sócios e sociedades comerciais, e de várias outras fontes. No mesmo ano foi editado o Regulamento $\mathrm{n}^{\circ} 737$, que disciplinava o processo relativo às causas comerciais, e nele também era prevista a utilização da arbitragem nos litígios comerciais (THEODORO JUNIOR, 2003, p.315).

Em 1867, o Decreto n 3.900 foi essencial para inviabilizar o uso da arbitragem no país. Tratou sobre o compromisso arbitral e em seu artigo $9^{\circ}$ dispôs que a cláusula de compromisso, sem a nomeação de árbitros, ou relativa a questões eventuais, não valia senão como promessa, e ficava dependente para sua perfeição e execução de novo e especial acordo das partes, não só sobre os requisitos elencados no artigo $8^{\circ}$, mas também sobre as declarações exigidas no artigo 10. (BRASIL, 2018, s.p).

Em 1891, o sistema constitucional brasileiro não previa a utilização da arbitragem em questões privadas, apenas referia-se a questões de âmbito internacional, a fim de pacificar as relações com outros Estados. Já o Código Civil de 1916 disciplinava o instituto nos artigos 1.037 a 1.048 .

Em 1939, o Código de Processo Civil, no Livro IX, tratou especificamente do instituto da arbitragem. Entretanto, nos anos seguintes, as Constituições de 1946, 1967 e 1969 ignoraram o importante instituto. 
O Código de Processo Civil de 1973 abordou o juízo arbitral em seu Capítulo XIV. Entretanto, os dispositivos elencados representavam obstáculos à sua aplicação. Assim, a cláusula compromissória existia como uma promessa de resolução de controvérsias futuras e eventuais, por meio dos árbitros, mas praticamente não produzia efeitos (MARCO, 2005, p.26).

Além disso, o procedimento da arbitragem era submetido ao Poder Judiciário, de modo que o laudo arbitral não possuía força legal se não homologado judicialmente (arts. 1.098 a 1.102), o que inviabilizava o reconhecimento de vantagens concretas para a utilização deste instituto, o qual continuava moroso, burocrático e dispendioso, justificando seu desuso. Nesse sentido:

\begin{abstract}
A necessidade de homologação do laudo arbitral doméstico, por sua vez, destruía as vantagens clássicas da arbitragem: o custo do processo acabava acrescido das despesas ocorridas com a demanda perante o Poder Judiciário; a celeridade esperada para a solução do litígio ficava comprometida, pois, apesar da simplicidade aparente do procedimento homologatório então vigente, a sentença proferida pelo juiz togado - oficializando ou não o laudo- desafiava recurso de apelação, que por sua vez, poderia abrir as portas ao recurso especial e (ou) ao recurso extraordinário; por derradeiro, o sigilo, que estimula a solução arbitral de conflitos, ficava prejudicado, já que a publicidade do processo estatal não preservava o segredo que as partes desejam manter acerca de sua desavença e relativamente à decisão dada pelo árbitro à questão por ela dirimida. (MARCO, 2005, p. 26).
\end{abstract}

\title{
3.1. A Lei 9.307/96 (Lei da Arbitragem)
}

Diante da necessidade de se atualizar a legislação brasileira, foi promulgada a lei 9.037 , de 23 de setembro de 1996 (Lei da Arbitragem), que alterou expressamente os dispositivos existentes, revogando toda a disciplina do Código Civil e Código de Processo Civil que tratava sobre o tema, e redefinindo o instituto sobre o prisma material e processual.

Com isso, foi fixada nova dimensão arbitral para o Brasil, criando condições favoráveis à sua aplicação definitiva nas resoluções de litígios, até então inexistentes, e consolidando-se como um instrumento legal de pacificação de conflitos, utilizado de maneira rápida e efetiva, tanto no âmbito interno como internacional.

Destaque-se, ainda, que a mencionada lei passou por reformas no ano de 2015, quando da edição da lei ${ }^{\circ} 13.129$, de 27 de maio, cujas alterações buscaram, dentre outros aspectos, expandir o campo da utilização da arbitragem, dispor sobre a escolha dos árbitros, permitir a 
concessão de tutelas cautelares e de urgência, além de tratar sobre a carta arbitral e a sentença arbitral, alterações que buscaram viabilizar, cada vez mais, a sua aplicação.

Sobre a Lei de Arbitragem é imprescindível afirmar que:

[...] o procedimento arbitral alternou em dois extremos: no primeiro, tinha uma vinculação obrigatória e, no segundo, passou a ser um compromisso facultativo. Tal situação somente foi se alterar com o surgimento da Lei 9.307/1996 que ainda permanece em vigência, pois ela definiu que a arbitragem uma vez convencionada torna provento o juízo arbitral, não cabendo mais à jurisdição estatal o poder de resolver o eventual litígio. (SPRENGLER; SPRENGLER NETO, 2016, p. 180)

A lei 9.307/96, antes de tudo, fortaleceu a cláusula compromissória, transformou o laudo arbitral em sentença arbitral, com a mesma eficácia de sentença judicial, e facilitou a homologação de laudos arbitrais estrangeiros, com o intuito de consolidar o instituto como uma viável solução de conflitos, alternativa ao Poder Judiciário. (MARCO, 2005 p. 26).

Logo em seu início, nos artigos $1^{\circ}$ e $2^{\circ}$, a lei definiu os aspectos objetivos e subjetivos da arbitragem, dispondo que somente as pessoas maiores e capazes podem procurar o juízo arbitral, bem como que o procedimento apenas abrangerá litígios relativos a direitos patrimoniais disponíveis ${ }^{5}$.

Deste modo, é possível confirmar o disposto pelo princípio da livre convenção entre as partes ou autonomia da vontade das partes, no qual se baseia o juízo arbitral. Assim, sabe-se que a arbitragem apenas ocorre entre pessoas com autonomia jurídica, capazes de concretizar suas relações jurídicas, e tem como objeto os bens disponíveis, ou seja, aqueles que os titulares podem livremente dispor (THEODORO JUNIOR, 2001, p. 316).

Ademais, ainda pelo princípio citado, às partes é permitido regular integralmente o procedimento arbitral e, inclusive, definir o direito material a ser empregado pelo árbitro, baseando-se tanto em leis nacionais como internacionais, desde que não ofendam a ordem pública e os bons costumes.

\footnotetext{
${ }^{5}$ Em 2015, com a lei no 13.129, passou-se a admitir que a Administração Pública Direta e Indireta se utilize da arbitragem para dirimir conflitos relativos a direitos patrimoniais disponíveis $\left(\operatorname{art.} 1^{\circ}, \S 1^{\circ}\right.$ ), aspecto não abordado no presente trabalho.
} 
Assim, a livre convenção entre os interessados engloba duas modalidades de negócio jurídico, ambas com força vinculantes e eficazes em substituir a movimentação da "máquina" do Judiciário. São elas a cláusula compromissória e o compromisso arbitral.

A Lei da Arbitragem estabeleceu que as partes capazes vão firmar, nos contratos, cláusula compromissória, submetendo o litígio à arbitragem. Nesse sentido, se na referida cláusula, as partes já obtiverem um acordo quanto às regras de um órgão arbitral institucional ou entidade especializada, o procedimento arbitral dar-se-á com base neste regramento. Porém, caso não ocorra seu pré-estabelecimento, a parte que almejar valer-se da arbitragem, deverá convocar a outra para que convencionem os termos do compromisso arbitral. (AMARAL, 2004, p. 337). No mais:

\begin{abstract}
O compromisso arbitral deverá necessariamente informar a qualificação das partes e dos árbitros (ou da instituição à qual foi delegada a indicação dos árbitros); a matéria que será objeto da arbitragem; o local em que será proferida a sentença arbitral (a legislação não mais se refere a laudo arbitral). Além disso, poderá o compromisso arbitral estipular o prazo para que seja proferida a decisão (caso contrário, será de seis meses), a autorização para que o árbitro (ou tribunal arbitral) julgue por equidade, com base no direito positivado brasileiro ou de outro país, nos princípios gerais do direito, nos usos e costumes ou práticas internacionais de comércio, ou ainda com base em regras corporativas aplicáveis à arbitragem. (AMARAL, 2004, p. 337).
\end{abstract}

Deste modo, fica definido que, a partir do momento em que as partes optam pelo juízo arbitral para a solução de um futuro litígio, e expressamente definem no contrato, esta via extrajudicial torna-se obrigatória.

Em relação à sentença arbitral, tornou-se definitiva, ou seja, é válida independente de homologação judicial. Quando condenatória, é considerada título executivo e é recorrível ao Judiciário apenas quando tratar-se dos aspectos formais, podendo ser requerida sua nulidade caso não respeite os requisitos da Lei de Arbitragem ou do próprio compromisso arbitral (art. 23 da lei 9.307/96).

Como a Lei da Arbitragem prevê que as próprias partes possam fixar o prazo para o árbitro proferir a sentença, ou, então, caso não o fizerem, será estabelecido o limite de seis meses para a tomada de decisão, este procedimento torna-se mais célere, que é mais uma de suas vantagens (art. 23).

Além disso, a arbitragem deve seguir alguns princípios do direito, tais como boa-fé, autonomia da vontade, imparcialidade dos árbitros, devido processo legal, contraditório e 
igualdade das partes, autonomia da cláusula compromissória, motivação das decisões, obrigatoriedade da sentença e acesso ao Judiciário.

Sobre a capacidade de ser árbitro, o artigo 13 da Lei de Arbitragem estabeleceu dois requisitos objetivos, quais sejam "deve ser pessoa física e capaz, que detenha a confiança das partes, não sendo um requisito obrigatório a formação do árbitro em direito, podendo ser um profissional da engenharia, medicina, contabilidade, administração ou qualquer outra conforme requeira o caso concreto" (FERREIRA; ROCHA; FERREIRA, 2019, p. 225).

No mais, é garantida às partes liberdade para convencionar pela arbitragem como forma de resolver seu litígio e pela escolha dos árbitros (em número ímpar) ou do tribunal arbitral de sua escolha. Ademais, a arbitragem possui natureza sigilosa (exceto nos casos envolvendo a Administração Pública), o que pode evitar a exposição pública de conflitos envolvendo pessoas ou empresas e, assim, possíveis constrangimentos, danos à imagem e, consequentes prejuízos. Esse caráter confidencial é de especial relevância em matérias do âmbito comercial, de família e mesmo trabalhista.

Assim, esses benefícios que a arbitragem traz podem ser aproveitados em vários litígios do contexto brasileiro, os quais, muitas vezes, demandam o sigilo, a celeridade e a especialidade que o Poder Judiciário não é capaz de oferecer. Observe-se que a economia da arbitragem, por sua vez, não se dá apenas para as partes, mas para toda sociedade que não vê mobilizado o aparato judiciário estatal para solução de controvérsias patrimoniais limitadas a particulares (AMARAL, 2004, p. 338).

Para que um litígio seja submetido ao juízo arbitral, é necessária uma convenção de arbitragem, ou seja, uma ligação jurídica composta pela cláusula compromissória e o compromisso arbitral. Francisco José Cahali compreende que "a convenção de arbitragem é referenciada na legislação arbitral como gênero, da qual são espécies a cláusula compromissória e o compromisso arbitral" (CAHALI, 2012, p. 111).

A cláusula compromissória está prevista no artigo $4^{\circ}$ da lei $\mathrm{n}^{\circ}$ 9.307/1996, tendo-lhe sido "atribuída a função de vincular a resolução do conflito à arbitragem" (SPRENGLER; SPRENGLER NETO, 2016, p. 188). Por sua vez, Antônio Carlos Rodrigues do Amaral descreve que "as partes capazes de contratar podem firmar cláusula compromissória prevendo 
a submissão à arbitragem, relativamente a direitos disponíveis, via de regra nos casos de disputas surgidas de relações contratuais" (AMARAL, 2004, p. 337). Deste modo, pode ser entendida como um acordo prévio que seleciona a arbitragem como método de resolução dos possíveis conflitos entre as partes contratantes.

Portanto, compreende-se que a cláusula compromissória é anterior à formação do litígio, existindo como uma promessa de comprometimento. Já o compromisso arbitral (arts. 10 e 11 da lei $n^{\circ}$ 9.307/96) celebra-se após a existência do litígio possuindo, dessa forma, significativo conteúdo contratual (VENOSA, 2002, p. 315) e diferenciando-se da cláusula arbitral pelo fato de ser instituído em face de um litígio concreto, ao passo que a primeira é anterior a qualquer disputa (DOLINGER; TIBURCIO, 2017, p. 633).

Assim, fica claro que tanto o compromisso arbitral quanto a cláusula compromissória têm o intuito de estabelecer a arbitragem, sendo, desta forma, aptos a impedir a movimentação da máquina judiciária, o que os torna recorrentes nos contratos internacionais de comércio, já que possibilitam uma maior celeridade e autonomia das decisões de seus possíveis litígios.

\section{A NOVA LEX MERCATORIA, OS CONTRATOS INTERNACIONAIS E A ARBITRAGEM}

No Brasil, considera-se comércio "exterior" quando uma das partes do contrato de compra e venda mercantil é empresário estabelecido no Brasil e a outra não. Deste modo, quando a venda é realizada por empresário estabelecido no Brasil, e o comprador, no exterior, essa relação é denominada exportação; ao contrário, se o comprador é brasileiro e o vendedor estrangeiro, ocorre importação (COELHO, 2012, p. 91).

Para que houvesse a garantia do desenvolvimento desse tipo de negócio, foi necessária certa padronização de direitos e deveres dos contratantes, a fim de evitar incertezas e o comprometimento da conclusão negocial, e contribuir para a prática de preços mais competitivos, aumento do volume de negociações e do consumo. 
Por essa razão, os próprios comerciantes passaram a utilizar, ao longo dos séculos, certos usos e costumes para solucionar eventuais conflitos de interesses, o que serviu de referência a outros comerciantes no fechamento de seus acordos comerciais. Esse importante regramento disciplinador das relações negociais foi denominado lex mercatoria. (COELHO, 2012, p. 91).

Surgida na Idade Média, o desenvolvimento da lex mercatoria deu-se para superar o regramento do sistema feudal sobre o comércio, sendo este considerado obsoleto. Assim, houve uma consolidação dos usos e costumes que regulamentavam as relações comerciais e, à medida que o comércio ultrapassava os limites nacionais, a lex mercatoria ganhava força.

Antônio Carlos Rodrigues do Amaral define essas regras em cinco aspectos: 1) transnacionalidade; 2) origem comum e fidelidade aos costumes mercantis; 3) eram aplicadas pelos próprios mercadores, por meio de suas corporações ou das cortes que se constituíam nos grandes mercados ou feiras; 4) seu procedimento era rápido e informal; e 5) enfatizavam a liberdade contratual e a decisão dos casos ex aequo et bono (AMARAL, 2004, p.59).

O uso dessa regulamentação mercantil foi se modificando ao longo dos séculos, devido às mudanças nas legislações nacionais dos países. Na Idade Moderna, as leis nacionais continentais mercantilistas efetivaram o Direito Comercial com a emergência dos códigos, mas marcaram o fim da velha lex mercatoria (AMARAL, 2004, p. 60).

Pedro Pontes de Azevedo elucida:

\begin{abstract}
Assim, na Idade Moderna, tendo em vista o fortalecimento das nações, o Estado invocou para si o monopólio legislativo, tendo como incompatíveis a produção legiferante estatal e as normas emanadas dos usos e costumes comerciais. As legislações nacionais se fortaleceram nesse período, ficando cada vez mais patenteada a imperatividade do direito comercial - que se firma, inclusive, como disciplina jurídica autônoma. Era advogada a tese de que a lex mercatoria era incompatível com o direito soberano de cada Estado produzir suas leis, ou seja, que um direito calcado em práticas, usos e costumes mercantilistas, de cunho supranacional, viria a mitigar a força normativa das leis nacionais. (AZEVEDO, 2006, p. 96).
\end{abstract}

Entretanto, não há de se falar, necessariamente, sobre o fim da "lei dos mercadores", e sim, sobre a modernização de seu conceito. A forte integração comercial e seu crescimento reafirmaram a necessidade desse regramento, o que promoveu o reconhecimento de seus instrumentos e estruturações legais. 
Assim, uma nova lex mercatoria tornou-se essencial para as relações comerciais, posto que apresentava mais vantagens práticas em seu procedimento que as próprias decisões judiciárias, já que as leis nacionais relacionadas a essas questões são, ainda, ineficientes para atender às necessidades dos comerciantes. Nesse sentido:

O processo de normatização do comércio internacional experimenta nos dias de hoje movimento espiral contínuo, que varia da autorregulação do comércio pelo próprio mercado à regulação do comércio pelo Estado. Naturalmente, o movimento de regulação do comércio pelo Estado, com a finalidade de se adequar às exigências do mercado, termina por criar ambiente mais favorável para o crescimento do comércio e para a atuação do mercado. Este, por sua vez, em virtude de sua liberdade de autorregulação, permanece na busca do aperfeiçoamento de suas práticas, recebendo do Estado regulamentação adaptativa, e assim sucessivamente. (VIDIGAL, 2010, p. 176).

Deste modo, embora a doutrina ainda não seja consolidada acerca da nova lex mercatoria, essa nova regulamentação pode ser compreendida como as regras costumeiras desenvolvidas em negócios internacionais aplicáveis em cada área determinada do comércio internacional, aprovadas e observadas regularmente (AMARAL, 2004, p. 61).

O Poder Judiciário brasileiro não tem por hábito a utilização da lex mercatoria como norma aplicável à solução de conflitos. José Carlos Magalhães e Agostinho Toffolli Tavolaro esclarecem que "os tribunais nacionais não a aceitam como corpo de leis alternativo a ser aplicado em um litígio. Acatando, estaria o Estado abdicando de parte de sua soberania em favor de mãos invisíveis de uma comunidade de mercados em constantes mudanças" (MAGALHÃES; TAVOLARO, 2004, p. 62). Em contrapartida, o instituto da arbitragem possui um forte vínculo com essa regulamentação comercial, o que possibilita vantagens nas resoluções de litígios do comércio.

Nesse sentido, a arbitragem pode ser compreendida como uma das estratégias de autovalidação dos contratos de comércio internacional situados no que seria o programa setorial da lex mercatoria, ou seja, aos usos práticos e imemoriais do comércio internacional (LEITE, 2015, p. 83).

No procedimento arbitral, com o princípio da autonomia da vontade, as partes têm ampla liberdade de escolher a forma de resolução dos conflitos e, por isso, a lei aplicável é aquela que mais atende aos interesses das categorias conflitantes. Com isso, é permitido o desígnio da lex mercatoria como direito aplicável para a resolução de um litígio proveniente do comércio internacional. 
Neste sentido, não havendo legislação específica a regular todas as relações jurídicoeconômicas, até em face da impossibilidade material de isso ocorrer, sobreleva-se a importância de regras supra-estatais que venham a dar conta de tal regulamentação. Neste diapasão, a adoção [de] um direito supranacional, fundado nos usos e costumes reiteradamente utilizados na prática internacional dos comerciantes - a lex mercatoria, seria uma forma de se estabelecer parâmetros concretos para a solução dos litígios surgidos no âmbito do comércio internacional. (AZEVEDO, 2006, p. 99).

Esse contexto de nova lex mercatoria coincide com a chamada "globalização", período no qual é intensificado o estabelecimento de contratos que envolvam pessoas ou empresas de diferentes localidades, que estão ligados por ordenamentos jurídicos distintos, ou seja, os contratos internacionais, assim conceituados por Irineu Strenger como:

[...] todas as manifestações bi ou plurilaterais da vontade livre das partes, objetivando relações patrimoniais ou de serviços, cujos elementos sejam vinculantes de dois ou mais sistemas jurídicos extraterritoriais, pela força do domicílio, nacionalidade, sede principal dos negócios, lugar do contrato, lugar da execução, ou qualquer circunstância que exprima um liame indicativo de Direito aplicável. (STRENGER, 1986, p. 81).

Sendo assim, se as partes contratantes possuem, cada uma, um sistema jurídico nacional diverso, o questionamento que se faz é sobre qual a lei aplicável em um contrato internacional. Além do direito aplicável ao contrato, é necessário saber como solucionar o conflito e de que modo o sistema jurídico de uma das partes vai utilizar a decisão judicial abalizada no direito da outra parte.

Nos Estados Unidos, após o caso específico "Sherk versus Alberto Culver", a Corte Suprema consolidou os aspectos necessários para a consideração de um contrato internacional, sendo eles: a nacionalidade das partes e o centro de seus interesses, o lugar das negociações, da assinatura e o da celebração (closing), e, por último, o objeto do contrato. (BAPTISTA, 2010, p. 27).

É importante salientar que, a norma aplicada ao contrato deve respeitar o ordenamento jurídico de todas as partes, ou seja, a lei de um país somente poderá ser aplicada em outro se sua legislação assim permitir. O Direito Internacional Privado (conflict law) é o responsável por solucionar possíveis conflitos de lei no espaço e o faz baseando-se nos elementos de conexão, ou seja, sobre questões relacionadas à capacidade das partes obrigadas, à obrigação em si, e aos aspectos extrínsecos ou intrínsecos da obrigação.

No ordenamento jurídico brasileiro, tais elementos estão dispostos na Lei de Introdução às Normas do Direito Brasileiro (LINDB - Decreto-lei $n^{\circ}$ 4.657/1942). A capacidade de 
contratar, ou seja, a aptidão para ser sujeito de direitos e obrigações, é relacionada à lei do domicílio dos contratantes (lex domicilii), e está prevista no artigo $7^{\circ}$ da referida norma. Quanto às normas aplicáveis às obrigações, foram previstas no art. $9^{\circ}$ do mesmo dispositivo legal, estabelecendo-se que "para qualificar e reger as obrigações, aplicar-se-á a lei do país em que se constituírem”.

Aos contratos internacionais, não obstante a aplicação de princípios tais como a igualdade soberana dos estados, a independência internacional, a boa-fé e a autonomia da vontade, o maior anseio, seja na perspectiva nacional, seja na internacional, é o seu efetivo cumprimento e, em caso de descumprimento, uma solução célere, barata e eficiente o que, conforme demonstrado, não vem sendo encontrado na estrutura do Poder Judiciário brasileiro, fator essencial do fortalecimento de soluções mais adequadas, como a arbitragem.

Ainda em relação à autonomia da vontade das partes, especificamente a respeito da possibilidade de escolherem a lei aplicável ao caso concreto, há que destacar que

\begin{abstract}
A escolha da lei deve ser negociada de boa-fé entre as partes, que poderão escolher como lei aplicável ao seu contrato em princípio, a lei do local em que se executará, a lei do local de sua celebração ou qualquer outra lei que julguem ser a ideal para regular a relação, inclusive leis de Estados neutros (ou seja, de nenhuma das partes envolvidas na negociação) ou, ainda um direito verdadeiramente internacional (como a Lex Mercatoria, os princípios Unidroit etc). A eleição do sistema legal é de suma importância, influenciando em muito o andamento de qualquer possível futura contenda; dessa forma as partes devem tomar bastante cuidado ao decidir esta questão. (ESTRELLA, 2009, p. 59).
\end{abstract}

Contudo, não obstante a inexistência de um regramento específico para os contratos internacionais, (GREBLER, 2008, p. 97) o Poder Judiciário brasileiro, nas controvérsias que lhe são submetidas, não permite às partes escolher livremente a lei material a ser aplicada, sujeitando-as à regra geral do art. $9^{\circ}$ da LINDB, supramencionado (PORTELA, 2016, p. 664).

\title{
5. A PRÁtiCA DA ARBITRAGEM NOS LITÍGIOS DO COMÉRCIO INTERNACIONAL BRASILEIRO
}


O avanço da globalização e a intensificação das relações internacionais do Brasil possibilitou o desenvolvimento do comércio além de suas fronteiras, que vem desempenhando um papel vital na economia. Assim:

A inserção do Brasil no cenário mundial em condições competitivas adequadas, detendo um regime jurídico e instrumentos legais modernos, justos, eficientes e compatíveis com os seus pares internacionais, sem dúvida ocorrerá para se alcançar o crescimento econômico sustentado, a harmonização das relações sociais e a tão almejada eliminação da exclusão de grande parcela dos brasileiros dos benefícios decorrentes da globalização. (AMARAL, 2004, p. 54).

A dinâmica comercial brasileira tem sido principalmente representada pelas exportações de commodities, que são os produtos que funcionam como matéria-prima, produzidos em larga escala e que podem ser estocados sem perderem a qualidade, como por exemplo, os de origem agrícola, como soja, milho e açúcar; os de origem ambiental, como madeira e água; os de origem mineral, como petróleo, etanol, ouro; e, ainda, os de origem financeira, como as moedas negociadas nos mercados.

Assim, as relações comerciais internacionais, de exportação e importação são vitais para a economia brasileira, sendo possível observar, ainda, a importância da exportação de produtos de origem primária para a economia nacional e, consequentemente, sua dependência externa de produtos com alta e média-alta intensidade tecnológica.

A lei brasileira sobre arbitragem não diferencia o regime jurídico dos procedimentos arbitrais internacionais realizados no Brasil, bem como não define um regime específico para a arbitragem internacional. Contudo, essa forma de solução de controvérsias é facilmente encontrada diante de relações jurídicas em que as partes contam com domicílios diversos, ou ainda, quando presente outro elemento de estraneidade, tal como o local do cumprimento da obrigação. Pode ser regulada pelo "direito interno de algum país, regras costumeiras ou princípios de comércio internacional” (DOLINGER; TIBURCIO, 2017, p 640). Neste sentido:

A ausência de disciplina da arbitragem internacional não impede a sua realização no Brasil, com ampla autonomia da vontade das partes. Surge a lacuna jurídica sobre as suas características, que devem ser supridas por analogia, costumes e princípios gerais de direito (artigo $4^{\circ}$ da LICC). Mas a sentença proferida em arbitragem internacional realizada no Brasil será uma sentença nacional (art. 34), que independerá da homologação pelo STJ, e toda sentença arbitral proferida fora do território internacional será considerada sentença estrangeira, sujeitando-se à homologação pelo STJ, para adquirir força executiva no Brasil. (ARAÚJO, 2003, p. 419). 
A aplicação da arbitragem internacional tem sido relevante nas relações privadas e, neste âmbito, é possível destacar seu uso nos conflitos que envolvem o comércio internacional, sobretudo diante da intensa participação do Brasil em blocos como o Mercosul., já que "o juízo arbitral representa uma importante válvula de escape à morosidade do Judiciário, além de possibilitar a prolação de sentenças tecnicamente mais embasadas, em virtude da competência específica dos árbitros eleitos pelas partes"(AZEVEDO, 2006, p. 101-102).

Consoante dados da Câmara de Comércio Internacional (CCI), (International Chamber of Commerce - ICC), organização internacional que auxilia o comércio global, o Brasil assumiu a posição do $5^{\circ}$ país que mais utiliza arbitragem no contexto global, em 2016 (VIVIANI, 2017, s.p.).

Ademais, conforme dispõe o Conselho Nacional das Instituições de Mediação e Arbitragem (CONIMA), entidade que objetiva estimular, unir e representar os órgãos que utilizam a mediação e a arbitragem, é possível notar também, no país, programas de incentivo à arbitragem, como o ocorrido entre 1999 e 2004, promovido pelo Banco Interamericano de Desenvolvimento (BID) em parceria com o Serviço Brasileiro de Apoio às Micro e Pequenas Empresas (SEBRAE) e a Confederação das Associações Comerciais e Empresariais no Brasil (CACB), com o objetivo de fortalecer as Câmaras de Arbitragem já existentes, bem como ampliar seu número.

As Câmaras de Arbitragem representam as estruturas responsáveis pela realização do procedimento arbitral, podendo ser apontadas como exemplos, no Brasil: o Centro Brasileiro de Litígios Econômicos (CBLE), além do Centro de Arbitragem da AMCHAM - Brasil (AMCHAM), o Centro de Arbitragem da Câmara de Comércio Brasil-Canadá (CAM-CCBC), a Câmara de Mediação, Conciliação e Arbitragem de São Paulo - CIESP/FIESP (CAMCIESP/FIESP), a Câmara de Arbitragem do Mercado - CAM-BOVESPA, localizados em São Paulo, a Câmara de Arbitragem da Fundação Getúlio Vargas (CAM-FGV), no Rio de Janeiro, e a Câmara de Arbitragem Empresarial - Brasil (CAMARB), em Belo Horizonte.

Consoante informa a pesquisa "Arbitragem em Números e Valores", entre os anos de 2010 e 2016, foi constatado um acréscimo de aproximadamente 95\% no número de novos procedimentos arbitrais no Brasil (LEMES, 2016, p.1). A pesquisa observou, também, as principais temáticas submetidas à arbitragem, sendo constatado que parte significativa dos 
novos casos referem-se a matérias societárias, contratos empresariais, contratos de fornecimento de bens e serviços e contratos de setores específicos, como o elétrico e o de mineração (LEMES, 2016, p. 2)

Além disso, foi verificado que em 2010, os valores envolvidos em arbitragem nas referidas Câmaras consultadas na pesquisa eram de $\mathrm{R}$ \$ 2,8 bilhões (dois bilhões e oitocentos milhões de reais) e em 2016 alcançaram $\mathrm{R} \$ 24,27$ bilhões (vinte e quatro bilhões e duzentos e setenta milhões de reais), ou seja, os valores nonuplicaram (LEMES, 2016, p. 2).

Foi constatado, ainda, que em 2015, o valor envolvido em soluções de litígios pelo procedimento arbitral nessas Câmaras, totalizou-se em R\$ 10.726.923.177,31 (dez bilhões, setecentos e vinte e seis milhões, novecentos e vinte e três mil, cento e setenta e sete reais e trinta e um centavos) e em 2016, $\mathrm{R} \$ 24.273 .202 .036,76$ (vinte e quatro bilhões, duzentos e setenta e três milhões, duzentos e dois mil, trinta e seis reais e setenta e seis centavos). O significativo volume destes valores presume que os novos conflitos abrangem contratos de grande porte (LEMES, 2016, p.2).

As controvérsias das relações de comércio internacional, em sua maioria, envolvem um enorme fluxo financeiro entre empresas transnacionais, apresentando grande relevância econômica para países distintos. Por essa razão, a lentidão na resolução dessas questões poderia causar relevante prejuízo, bem como refletir negativamente em toda a economia global. Beat Walter Rechsteiner afirma que:

\footnotetext{
Atualmente, estima-se que cerca de $90 \%$ dos contratos internacionais de comércio contêm uma cláusula arbitral. Em contratos internacionais referentes à construção de complexos industriais e projetos de construção similares, o índice de cláusulas arbitrais, inseridas nestes contratos, atinge a cerca de $100 \%$. Neste terreno, a decisão das lides decorrentes de tais relações jurídicas é atribuída, basicamente, a tribunais arbitrais e não aos tribunais estatais. (RECHSTEINER, 2001, p. 15).
}

Vale destacar novamente o quanto o caráter sigiloso do juízo arbitral também representa um benefício para os interesses do comércio internacional, pois, além de impedir a exposição dos valores envolvidos nas negociações, evita possíveis constrangimentos aos litigantes. Para Beat Walter Rechsteiner:

Uma grande vantagem da arbitragem é seu caráter sigiloso e confidencial. As audiências perante a justiça estatal costumam ser públicas. Destarte, a imagem das partes envolvidas no processo pode ser prejudicada perante o público. Eventualmente 
também concorrentes diretas das partes podem levar vantagens sobre ambas delas em virtude da publicidade do processo. (RECHSTEINER, 2001, p. 27).

Em relação aos custos, ainda que a utilização da arbitragem possa, em uma análise imediata, ser mais onerosa que o recurso ao Poder Judiciário, a doutrina destaca as vantagens oriundas do "custo de oportunidade", que "leva em consideração o tempo em que o valor em litígio ficará imobilizado em virtude da demora da duração da solução da lide" (FERREIRA; ROCHA; FERREIRA, 2019, p. 38).

A arbitragem já é satisfatoriamente utilizada por diferentes países, como nos Estados Unidos, na França, Alemanha, Espanha, Suíça, Suécia e Bélgica, o que também viabiliza a aplicação deste método extrajudicial nos casos internacionais.

No sistema francês, assim como na Suíça, Suécia, Tunísia e Bélgica, houve discussão sobre a anulação da sentença arbitral. Assim, o Código Processual Civil francês passou a garantir, em seu artigo 1.522, que as partes pudessem afastar contratualmente a propositura de anulação do laudo, no caso da arbitragem internacional sediada no país (DOLINGER; TIBURCIO, 2017, p. 642). Sobre isto, Jacob Dolinger e Carmem Tiburcio esclareceram:

Essa possibilidade conferida aos participantes de uma arbitragem internacional se justifica em virtude do fato de que tais laudos serão executados em outro país, onde estarão sujeitos ao controle com base na convenção de Nova York, art. V. Portanto, ainda que não sejam passíveis de anulação na França, o laudo pode ser afastado no país de sua execução, caso esteja presente alguns dos requisitos previstos na requerida convenção. (DOLINGER; TIBURCIO, 2017, p. 642).

No Brasil, por sua vez, a anulação é prevista no artigo 33 da Lei 9.307/96, o qual dispõe:

Art. 33. A parte interessada poderá pleitear ao órgão do Poder Judiciário competente a declaração de nulidade da sentença arbitral, nos casos previstos nesta Lei.

$\S 1^{\circ}$ A demanda para a declaração de nulidade da sentença arbitral, parcial ou final, seguirá as regras do procedimento comum, previstas na Lei no 5.869 , de 11 de janeiro de 1973 (Código de Processo Civil), e deverá ser proposta no prazo de até 90 (noventa) dias após o recebimento da notificação da respectiva sentença, parcial ou final, ou da decisão do pedido de esclarecimentos.

§ 2o A sentença que julgar procedente o pedido declarará a nulidade da sentença arbitral, nos casos do art. 32, e determinará, se for o caso, que o árbitro ou o tribunal profira nova sentença arbitral.

$\S 3^{\circ} \mathrm{A}$ decretação da nulidade da sentença arbitral também poderá ser requerida na impugnação ao cumprimento da sentença, nos termos dos arts. 525 e seguintes do Código de Processo Civil, se houver execução judicial.

§ 40 A parte interessada poderá ingressar em juízo para requerer a prolação de sentença arbitral complementar, se o árbitro não decidir todos os pedidos submetidos à arbitragem. 
É importante salientar, ainda, que a lei brasileira da arbitragem estabelece que "a sentença arbitral estrangeira será reconhecida ou executada no Brasil de conformidade com os tratados internacionais com eficácia no ordenamento interno e, na sua ausência, estritamente de acordo com os termos desta lei” (art. 34). Desta forma, tem-se aqui uma situação de prevalência do Direito Internacional sobre o interno, conforme previsão feita pelo próprio legislador doméstico, fazendo com que as regras sobre o reconhecimento de sentenças arbitrais estrangeiras previstas na lei só sejam aplicadas na ausência de disposição em tratado internacional (DOLINGER; TIBURCIO, 2017, p. 646).

Dentre os tratados, é possível destacar a Convenção de Nova York (1958), a qual é utilizada no Brasil (Decreto 4.311, de 23 de julho de 2002) sem reservas e foi ratificada por um total de 149 países, o que simboliza uma uniformidade no direito sobre reconhecimento e execução de laudos arbitrais alienígenas (DOLINGER; TIBURCIO, 2017, p. 646).

É possível concluir que as interconexões presentes nas sociedades atuais, acarretadas pela constante globalização, se intensificam cada vez mais, e movimentam as estruturas de diversos países. Com isso, é necessária a modernização destas relações, a fim de facilitar sua realização, como garantia de melhorias sociais, técnicas e, principalmente, econômicas.

Nesse sentido, a arbitragem pode ser avaliada como um facilitador dessas relações, com o intuito de viabilizar que os possíveis litígios que envolvam direitos patrimoniais disponíveis sejam rapidamente e qualificadamente solucionados.

Diante do exposto, constata-se que a aplicação da arbitragem possibilita um vasto número de benefícios práticos aos litigantes, ao fluxo do procedimento decisório, ao resultado e às suas consequências, devendo ser este instituto cada vez mais estimulado, em detrimento da movimentação da máquina do Judiciário, a fim de afetar positivamente, dentre outras, as relações jurídicas concernentes ao comércio internacional. 


\section{CONSIDERAÇÕES FINAIS}

O presente artigo buscou evidenciar as vantagens de se adotar a arbitragem como meio adequado à solução de controvérsias envolvendo o comércio internacional no direito brasileiro.

Destacou-se que, não obstante a conquista decorrente da facilitação no acesso ao Poder Judiciário, tal fenômeno foi acompanhado por um desmedido acúmulo de processos, o que tornou o sistema cada vez mais moroso, prejudicando a solução de litígios que demandam respostas céleres, tais como aqueles envolvendo contratos internacionais do comércio.

Assim, pôde-se observar que há no cenário jurídico brasileiro atual a intensificação da necessidade de se optar por métodos extrajudiciais de solução de controvérsias, tais como a arbitragem, a mediação e a conciliação, no intuito de desafogar o sistema judiciário e dar celeridade e qualidade à obtenção da solução de conflitos.

A arbitragem, prevista na Lei 9.307, de 23 de setembro de 1996 (Lei da Arbitragem), é um dos mais importantes métodos legais extrajudiciais, alternativos ao Poder Judiciário, adequado à resolução de conflitos que envolvem os direitos patrimoniais disponíveis no Brasil. Se duas pessoas capazes ou empresas têm uma questão a ser resolvida, como o cumprimento de um contrato, elas podem abrir mão de procurar a justiça convencional e escolher uma terceira pessoa para decidir sobre o problema, tendo essa decisão a mesma validade que a judicial. Deste modo, compreender esse instituto tornou-se assunto de amplo interesse econômico, empresarial e social.

Assim, ao envolverem significativas cifras, os litígios oriundos do comércio internacional não serão, em regra, satisfatoriamente sanados, se submetidos ao lento e pouco especializado Poder Judiciário brasileiro, exigindo-se, via de regra, a agilidade e especialidade inerentes à solução via arbitragem.

Conforme disposição da lei brasileira de arbitragem, nesse procedimento, as partes escolhem os árbitros, sendo, portanto, possível que um profundo entendedor do assunto decida o caso, prescindindo-se da formação jurídica. Também é possível ajustar as regras do procedimento às necessidades dos litigantes, já que as partes podem escolher a lei aplicável. No 
mais, pode ser decidido sobre o sigilo do procedimento, e a confidencialidade pode ser muito útil às questões do comércio internacional, quando se trata de segredos de negócios, conflitos societários ou quando as partes não desejam a exposição de suas informações.

A celeridade também é um dos fatores essenciais, já que as próprias partes determinam os prazos e, quando não, a lei dispõe que a decisão será proferida em seis meses. Além disso, a arbitragem pode ser menos onerosa, principalmente quando os contratos envolvem uma grande quantidade de bens e valores, considerando-se o que a doutrina chama de "custo de oportunidade".

Ademais, seguindo uma tendência internacional, a arbitragem vem ganhando cada vez mais espaço no Brasil, mediante a inclusão de cláusulas compromissórias ou compromissos arbitrais em um número crescente de contratos envolvendo partes brasileiras, o que possibilita, dentre outros aspectos, o afastamento da aplicação automática da vetusta regra estampada no art. $9^{\circ}$ da Lei de Introdução às Normas do Direito Brasileiro que determina a aplicação exclusiva da norma do local da celebração de eventuais contratos internacionais.

Outrossim, a arbitragem internacional representa o modo de solução de controvérsias mais compatível com a chamada "nova lex mercatoria", na medida em que proporciona um procedimento para além das fronteiras, possibilitando a fluidez e segurança das relações comerciais, que acompanham a globalização.

Evidencia-se, dessa forma, que a arbitragem, mais que um meio alternativo, mostra-se como o meio mais adequado na solução de conflitos envolvendo o comércio interacional no Brasil, imprescindível para se proporcionar a segurança jurídica e a estabilidade das relações jurídicas necessárias a que o país retome os rumos do crescimento e do desenvolvimento econômico e social. 


\section{REFERÊNCIAS BIBLIOGRÁFICAS}

AMARAL, Antonio Carlos Rodrigues do (coord.). Direito do Comércio Internacional: aspectos fundamentais. São Paulo: Aduaneiras, 2004.

ARAUJO, Nadia de. A nova lei de arbitragem brasileira e os princípios uniformes dos contratos comerciais internacionais, elaborados pelo UNIDROIT. In: CASELLA, Paulo Borba (coord.). Arbitragem: a nova lei brasileira (9.307/96) e a praxe internacional. São Paulo: LTr, 1997.

ARAUJO, Nadia de. Direito Internacional Privado: teoria e prática brasileira. Rio de Janeiro: Renovar, 2003.

AZEVEDO, Pedro Pontes de. A lex mercatoria e sua aplicação no ordenamento jurídico brasileiro. Prima facie, ano 5, n. 9, jul./dez. 2006.

BAPTISTA, Luiz Olavo. Contratos Internacionais. São Paulo: Lex, 2010.

BRASIL, CNJ. Relatório de Justiça em Números. 2018, p. 74. Disponível em: < http://www.cnj.jus.br/files/conteudo/arquivo/2018/09/8d9faee7812d35a58cee3d92d2df2f25.p df>. Acesso em: 7 nov. 2018.

BRASIL, Lei n. 9.307, de 23 de setembro de 1996. Institui a Lei da Arbitragem. Disponível em: <http//www.planalto.com.>. Acesso em: 26 jun. 2018.

BRASIL, Portal da Câmara dos Deputados. Disponível em: 〈http.www2.camara.leg.br>. Acesso em 10 set. 2018.

CAHALI, Francisco José. Curso de arbitragem: mediação, conciliação, Resolução CNJ 125/ 2010. 2. ed. São Paulo: Revista dos Tribunais, 2012.

COELHO, Fabio Ulhoa. Curso de Direito Comercial, v.2. 16. ed. São Paulo: Saraiva, 2012.

DOLINGER, Jacob; TIBURCIO, Carmem. Direito Internacional Privado. 13. ed. Rio de Janeiro: Forense, 2017.

ESTRELLA, Angela T. Gobbi; TIMM, Luciano Benetti; RIBEIRO, Rafael Pellegrini. Direito do Comércio Internacional. Rio de Janeiro: FGV, 2009.

FERREIRA, Olavo Augusto Vianna Alves; ROCHA, Matheus Lins; FERREIRA, Débora Cristina Fernandes Ananias Alves. Lei de Arbitragem comentada artigo por artigo. Salvador: Juspodivm, 2019.

FIGUEIRA JUNIOR, Joel Dias. Arbitragem, jurisdição e execução: análise crítica da lei 9.307, de 23.09.1996. 2. ed. São Paulo: RT, 1999.

FREITAS, Juarez; JOBIM, Marco Felix. Resolução alternativa de disputas: cláusula inovadora do CPC. Revista brasileira de Direito Processual. Belo Horizonte, ano 23, n. 91, p. 97- 112, jul./set. 2015. 
GREBLER, Eduardo. A Convenção das Nações Unidas sobre Contratos de Venda Internacional de Mercadorias e o Comércio Internacional Brasileiro. III Anuário Brasileiro de Direito Internacional. v.1, 2008.

LEITE, Guilherme Cardoso. Lex mercatoria, arbitragem internacional e democracia: reflexões acerca da utilização dos usos do comércio transnacional enquanto fundamento válido e democrático para a resolução de conflitos por meio da arbitragem internacional. Disponível em: <file:///C:/Users/Windows\%207/Downloads/3492-16101-2-PB.pdf>. Acesso em: 31 out. 2018.

LEMES, Selma Ferreira. Arbitragem em Números e Valores. Acesso em: Disponível em: < http://selmalemes.adv.br/artigos/An\%C3\%A1lise-\%20Pesquisa-

$\% 20$ Arbitragens\%20Ns\%20\%20e\%20Valores\%20_2010\%20a\%202016_.pdf>. Acesso em: 22 out. 2018.

MAGALHÃES, José Carlos; TAVOLARO, Agostinho Toffolli. Fontes do direito do comércio internacional: a lex mercatoria. In: AMARAL, Antonio Carlos Rodrigues (Org.). Direito do comércio internacional: aspectos fundamentais. São Paulo: Aduaneiras, 2004.

MARCO, Carla Fernanda de. Arbitragem internacional no Brasil. São Paulo: RCS, 2005.

MOREIRA, Helena Delgado Ramos Fialho. Poder Judiciário no Brasil: crise e eficiência. Curitiba: Juruá, 2009.

NERY JUNIOR, Nelson. Código de Processo Civil Comentado. 3. ed. São Paulo: RT, 2008.

PEREIRA, Lafayette Rodrigues. Princípios de Direito Internacional. Belo Horizonte: Assembleia Legislativa do Estado de Minas Gerais, 2017.

PORTELA, Paulo Henrique Gonçalves. Direito Internacional Público e Privado: incluindo noções de Direitos Humanos e de Direito Comunitário. 8.ed. Salvador: JusPodivm, 2016.

RECHSTEINER, Beat Walter. Arbitragem privada internacional no Brasil depois da Lei 9.307, de 23.09.1996: teoria e prática. 2. ed. São Paulo: RT, 2001.

RESEK, Francisco. Direito Internacional Púbico: curso elementar. 11.ed. São Paulo: Saraiva, 2008.

RIBEIRO, Gustavo Pereira Leite. Arbitragem nas relações de consumo. Curitiba: Juruá, 2006.

SCHMITTHOFF, Clive M. Schmittoff's Export Trade: the law and practice of internacional trade. 9. ed. London: Stevens and Sons, 1990, p. 649-652.

SPENGLER, Fabiana Marion; SPENGLER NETO, Theobaldo. Mediação, Conciliação e Arbitragem: artigo por artigo de acordo com a Lei $n^{\circ} 13.140 / 2015$, Lei ${ }^{\circ} 9.307 / 1996$, Lei $n^{\circ}$ 13.105/2005 e com a Resolução ${ }^{\circ}$ 125/ 2010 do CNJ (Emendas I e II). Rio de Janeiro: FGV, 2016. 
STRENGER, Irineu. Direito do Comércio Internacional e Lex Mercatoria. São Paulo: LTr, 1996.

THEODORO JUNIOR, Humberto. Curso de Direito Processual Civil. Rio de Janeiro: Forense, 2003.

TRISTÃO, Ivan Martins; FACHIN, Zulmar. O acesso à justiça como direito fundamental e a construção da democracia pelos meios alternativos de solução de conflitos. Londrina: Scientia Iuris, 2009.

VIDIGAL, Erick. A lex mercatoria como fonte do direito do comércio internacional e sua aplicação no Brasil. Revista de informação legislativa. Brasília a. 47 n. 186 abr./jun. 2010. p. 171-193.

VIVIANI, Luis. BRASIL É O 5 PAÍS QUE MAIS UTILIZA A ARBITRAGEM NO MUNDO. Dados de 2016 são da Câmara de Comércio Internacional. Litígios globais somam US\$ 171 bilhões. Disponível em: https://www.jota.info/justica/brasil-e-o-5o-pais-que-mais-utilizaarbitragem-no-mundo-19092017>. Acesso em: 22 out. 2018.

VENOSA, Sílvio de Salvo. Direito Civil. v. 2. 2. ed. São Paulo: Atlas, 2002.

VILELA, Danilo Vieira. O papel da Antaq na solução de conflitos envolvendo a demurrage de contêiner. In: CASTRO JUNIOR, Osvaldo Agripino. Teoria e prática da demurrage de contêiner. São Paulo: Aduaneiras, 2018. p. 265-283.

WLADECK, Felipe Scriepes; AMARAL, Paulo Osternak. Arbitragem no Brasil. Revista Brasileira de Direito Processual - RBDPro. Belo Horizonte, ano 19, n. 74, abr./jun. 2011.

Data de Submissão: 27/04/2020

Data de Aceite: 15/05/2020 